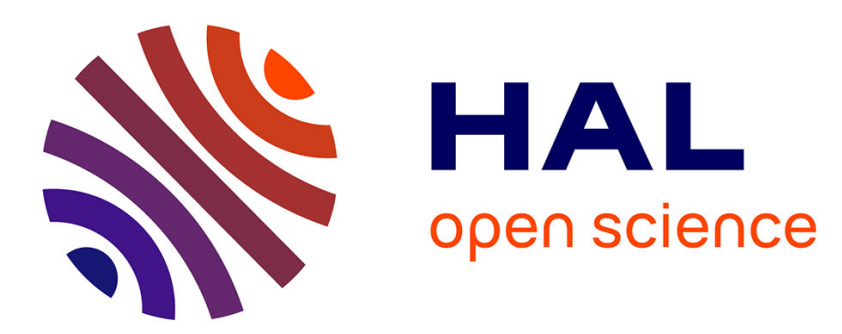

\title{
Effect of intracortical bone properties on the phase velocity and cut-off frequency of low-frequency guided wave modes $(20-85 \mathrm{kHz})$
}

Daniel Pereira, Guillaume Haiat, Julio C. Fernandes, Pierre Belanger

\section{- To cite this version:}

Daniel Pereira, Guillaume Haiat, Julio C. Fernandes, Pierre Belanger. Effect of intracortical bone properties on the phase velocity and cut-off frequency of low-frequency guided wave modes (20-85 $\mathrm{kHz}$ ). Journal of the Acoustical Society of America, 2019. hal-02388263

\section{HAL Id: hal-02388263 https://hal.science/hal-02388263}

Submitted on 1 Dec 2019

HAL is a multi-disciplinary open access archive for the deposit and dissemination of scientific research documents, whether they are published or not. The documents may come from teaching and research institutions in France or abroad, or from public or private research centers.
L'archive ouverte pluridisciplinaire HAL, est destinée au dépôt et à la diffusion de documents scientifiques de niveau recherche, publiés ou non, émanant des établissements d'enseignement et de recherche français ou étrangers, des laboratoires publics ou privés. 


\section{Effect of intracortical bone properties on the phase velocity and cut-off frequency of} low-frequency guided wave modes $(20-85 \mathrm{kHz})$

Daniel Pereira, 1, a) Guillaume Haiat, ${ }^{2, b}$ Julio Fernandes, ${ }^{3, c}$ and Pierre Belanger ${ }^{1, d}$

${ }^{1}$ Department of Mechanical Engineering, École de technologie supérieure, 1100 Rue Notre-Dame O, Montreal, Quebec, H3C1K3 Canada

${ }^{2}$ CNRS, Laboratoire Modélisation et Simulation Multiechelle, UMR CNRS 8208, 61 avenue du Général de Gaulle, Cretéil Cedex, 94010,

France

${ }^{3}$ Centre de recherche l'Hôpital du Sacré-Coeur de Montréal, 5400 Boul Gouin O, Montreal, Quebec, H4J1C5 Canada 

The assessment of intracortical bone properties is of interest since early-stage osteoporosis is associated with resorption in the endosteal region. However, understanding the interaction between ultrasonic guided waves and the cortical bone structure remains challenging. The purpose of this work is to investigate the effect of intracortical bone properties on the ultrasonic response obtained at low-frequency $(<100 \mathrm{kHz})$ using an axial transmission configuration. The semi-analytical finite element method was used to simulate the propagation of guided waves in a waveguide with realistic geometry and material properties. An array of 20 receivers was used to calculate the phase velocity and cut-off frequency of the excited modes using the 2D Fourier transform. The results show that the position of the emitter around the circumference of the bone is an important parameter to control since it can lead to variations of up to $10 \mathrm{~dB}$ in the amplitude of the transmitted modes. The cut-off frequency of the high order modes was, however, only slightly affected by the circunferential position of the emitter, and was sensitive mainly to the axial shear modulus. The phase velocity and cut-off frequency in the $20-85 \mathrm{kHz}$ range are promising parameters for the assessment of intracortical properties.

a)daniel.pereira.1@ens.etsmtl.ca; Also at: Centre de recherche l'Hôpital du Sacré-Coeur de Montréal, 5400 Boul Gouin O, Montreal, Quebec, H4J1C5 Canada

${ }^{\mathrm{b}}$ Also at: Department of Mechanical Engineering, École de technologie supérieure, 1100 Rue Notre-Dame O, Montreal, Quebec, H3C1K3 Canada

${ }^{c}$ Also at: Department of Surgery, Université de Montréal, 2900 Boulevard Edouard-Montpetit, Montreal, Quebec, H3T1J4 Canada

dAlso at: Centre de recherche l'Hôpital du Sacré-Coeur de Montréal, 5400 Boul Gouin O, Montreal, Quebec, H4J1C5 Canada 


\section{INTRODUCTION}

Osteoporosis is associated with a reduction of the bone mass and microarchitectural bone deterioration, leading to a reduction in bone quality (Giangregorio et al., 2006; Papaioannou et al., 2004; Ström et al., 2011) and to an increase in fracture risk (Consensus development conference: prophylaxis and treatment of osteoporosis, 1991). Endosteal resorption of cortical bone results in an increase in bone porosity at the inner part of the cortical shell and in a reduction of the cortical bone thickness (Ritzel et al., 1997). Dual-energy X-ray absorptiometry (DEXA), which is currently the gold standard for osteoporosis diagnostics (Kanis, 1994), nonetheless suffers from several limitations (Gluer, 2008; Haba et al., 2016). Quantitative ultrasound (QUS) was developed to assess bone quality and has the advantage of being non-radiative, non-invasive and relatively cheap (Gluer, 1997). It, therefore, holds promise as a rapid screening method in a clinical setting. The mechanical nature of ultrasonic waves allows the technique to be used to retrieve the biomechanical properties of bone tissue (Kaufman and Einhorn, 1993). QUS techniques can be used to go beyond a simple estimation of the bone mineral density (Nicholson, 2008), which can be achieved with DEXA and which is not sufficient to assess fracture risk (Office of the Surgeon General, 2004).

Bone QUS was initially developed in the context of trabecular bone characterization using transverse transmission devices (Stein et al., 2013). However, the investigation of cortical bone (Rico, 1997) has attracted significant interest since about $80 \%$ of the skeleton is made of cortical bone, which supports most of the body load, and is involved in osteoporotic 
fractures (Seeley et al., 1991). QUS using axial transmission techniques have mostly been used to study the cortical bone quality (Haiat et al., 2011). Cortical bones, such as the radius or the tibia, constitute suitable waveguides for the propagation of ultrasonic guided waves, as has was shown in various studies, including for instance (Gluer, 2008, 1997; Haba et al., 2016). Ultrasonic guided waves have the advantage of being sensitive to both the mechanical and geometrical properties of cortical bone (Foiret et al., 2014; Muller et al., 2005; Rozental et al., 2013).

Most studies focusing on the assessment of cortical bone properties using axial transmission consider plate or cylinder waveguides (as an approximation of the actual bone geometry) to simplify the interpretation of ultrasonic responses obtained numerically or experimentally (Kilappa et al., 2015; Le et al., 2010; Minonzio et al., 2015; Xu et al., 2016). Recently, more comprehensive numerical approaches were explored with the aim of improving the realism of the effect of cortical bone features on the axial transmission propagation expected in vivo. Bossy et al. (2004) (Bossy et al., 2004) performed three-dimensional (3D) finite difference simulations on geometries derived from a human radius tomography image to evaluate the effect of bone curvature, anisotropy, and micro-porosity on the first arriving signal (FAS) velocity. However, the actual anatomical variations of bone biomechanical properties were not taken into account and more emphasis was brought to the analysis of numerical simulations performed with idealized 3D objects (tubes and semi-infinite hemicylinder geometries). Moilanen et al. (2007) (Moilanen et al., 2007) developed a 2D numerical bone model to investigate the impact of realistic bone geometry specimens on the ultrasonic cortical thickness evaluation using plate assumptions. Haiat et al. (2009) (Haïat et al., 2009) (Haiat et al., 
2011) and Naili et al. (2010) (Naili et al., 2010) assessed the effect of the heterogeneous nature of the cortical bone on the axial transmission response at $1 \mathrm{MHz}$ in the framework of an anisotropic material by using 2D finite element (FE) simulation on a plate model. More recently, Chen et al. (2014) (Chen and $\mathrm{Su}, 2014$ ) proposed a quantitative compensation for the effect of soft tissues based on an in vitro calibration, which facilitates the development of high-precision measurements of guided wave modes. Moreau et al. (2015) (Moreau et al., 2014) introduced a modified method to predict the dispersion curves of an isotropic plate waveguide with a linearly varying thickness along the propagation direction. The method allowed the detection of enhanced and more accurate wavenumbers in the context of the formulation of inverse problems. Recently, Tran et al. (2018) (Tran et al., 2018) performed a numerical study to evaluate the effect of cortical thickness, stiffness coefficient, and thickness of the overlying soft tissues on the responses of fundamental ultrasonic guided waves in the frequency domain, using a homogeneous transversely isotropic tri-layered plate model. However, despite the improvements achieved so far concerning the modeling of cortical bone, a more detailed numerical study remains needed to explain the influence of the cross-sectional curvature and distribution of properties in the radial direction on the propagation of the guided waves at low-frequency.

Low-frequency (typically below $200 \mathrm{kHz}$ ) axial transmission research (Egorov et al., 2014; Kilappa et al., 2011; Sarvazyan et al., 2009; Tran et al., 2015) demonstrated that ultrasonic guided waves are sensitive to changes in bone properties, such as the cortical thickness and the porosity. Muller et al. (2005) (Muller et al., 2005) introduced low-frequency axial transmission as a promising method for assessing the cortical thickness. Tatarinov et al. 
(2005) (Tatarinov et al., 2005) showed the potential of low-frequency ( $\approx 100 \mathrm{kHz})$ in assessing changes of deep underlying spongy layers in bovine tibia. More recently, Killappa et al. (2015) (Kilappa et al., 2015) reported an improved performance of fundamental flexural modes used to assess cortical bone thickness using phase-delayed excitation at very lowfrequency $(50 \mathrm{kHz})$. Kassou et al. (2017) (Kassou et al., 2017) investigated the feasibility of dry point-contact transducers to infer the thickness of the in-vivo subjects in the 50-150 $\mathrm{kHz}$ frequency range. Operating at low-frequency offers the advantage of a lower attenuation as well as a reduced number of generated modes, which simplifies the signal analysis. In addition, low-frequency guided wave modes tend to achieve greater penetration depths due to the longer wavelengths as compared to high-frequency. As a consequence, the sensitivity to variations in intracortical bone properties could be improved when using low-frequencies, which is relevant to assess early stages of osteoporosis. Notwithstanding the remarkable level of realism that has been introduced in simulations over the past few years, the physical interaction between low-frequency guided waves and the cortical bone structure remains unexplored because the cortical bone has i) a complex cross-sectional geometry and ii) a heterogeneous distribution of material properties along the circumferential direction.

In a previous study by our group (Pereira et al., 2017), the propagation of guided waves in an irregular, multi-layer and heterogeneous bone cross-section modeled with anisotropic and viscoelastic material properties was investigated. The effect of the intracortical bone properties was then evaluated using the first arriving signal (FAS) velocity obtained from only five receivers. However, due to the interaction between several modes around the FAS, the velocity associated with the FAS was shown to be a poor discriminator of the 
intracortical bone properties. The goal of this paper is therefore to determine the effect of intracortical bone properties on the phase velocity and cut-off frequency of low-frequency guided wave modes using an array of receivers, as well as a time-spatial frequency analysis technique instead of the FAS velocity. In order to do so, the excitation was generated by an emitter while the acquisition was performed in the time domain by an array of 20 receivers equally spaced along the bone surface. The bone ultrasonic responses were converted into the frequency domain using the two-dimensional Fourier transform (2D-FFT) in order to obtain the phase velocity and cut-off frequency of the propagating modes. Therefore, in this paper, the individual contribution of each viscoelastic coefficient and of the density was evaluated separately. The originality of this study when compared to our previous publication also lies in the application of the excitation source at different positions on the bone surface. This leads to a more comprehensive understanding of the physical interaction between the cortical bone curvature and the excitability of low-frequency guided wave modes.

The paper is organized as follows: section II.A introduces the semi-analytical finite element (SAFE) method used to simulate the signal of ultrasonic guided waves propagation in an arbitrary cross-section waveguide; section II.B describes the emitter/receivers configuration used to measure the ultrasonic responses on the bone surface in order to compute the frequency vs. wavenumber diagram. This section also describes the procedure employed to derive the phase velocity and cut-off frequency from the measured diagrams. In section II.C and II.D, the cross-sectional geometry of the cortical bone model and the methodology used to define the distribution of properties along the radial direction are presented respectively. Section II.E focuses on the description of the experimental work performed on bone phan- 
toms that was done in order to verify the robustness and accuracy of the SAFE simulations.

In section III.A, the effect of the excitation position and the physiopathological condition on the phase velocity and cut-off frequency are presented. In addition, the individual contribution of each viscoelastic coefficient and density on the overall physiopathological conditions are presented in the section III.B. Conclusion including potential clinical implications are presented in section IV.

\section{MATERIAL AND METHODS}

\section{A. Simulating time domain signals}

The SAFE method has recently been used to simulate the modal properties of the ultrasonic guided wave in bone systems (Nguyen and Naili, 2014; Nguyen et al., 2017; Thakare et al., 2017; Tran et al., 2015). The computation of the time response from the modal properties of waveguides in an infinite arbitrary cross-section waveguide was previously described by Wilcox et al. (Wilcox et al., 2001) and Loveday (Loveday, 2008). The resulting time domain signals consist in a linear superposition of the propagated response of each mode supported by the waveguide. A more detailed description of the implementation of the SAFE method can be found in the literature (Fan et al., 2008; Predoi et al., 2007), while the detailed procedure used to generate the time domain signal, can be found in a recently published study (Pereira et al., 2017).

The dispersive response of a given mode excited from a point source in the out-of-plane direction (radial direction $r$ in Fig. 1) can be calculated in the time domain using the 
following expression (Wilcox et al., 2001):

$$
\begin{gathered}
u(t)=\frac{1}{2 \pi} \int_{-\infty}^{+\infty} F(\omega) E(\omega) H_{0}^{(1)}\left(k(\omega) z_{0}\right) e^{-i \omega t} d \omega \\
i=\sqrt{-1}
\end{gathered}
$$

where $u(t)$ is the surface out-of-plane displacement for a given mode as a function of time $t$, for an arbitrary propagation distance $z_{0}$. The term $H_{0}^{(1)}$ is the zeroth-order Hankel function of the first kind and $F(\omega)$ is the frequency spectrum of a force input signal $u_{\text {input }}(t)$. The term $k(\omega)$ is the mode wavenumber, defined as a complex number by:

$$
k(\omega)=k(\omega)_{\text {real }}+i k(\omega)_{i m a g}
$$

where the real part denotes the propagating term and the imaginary part denotes the attenuation associated with the wavenumber. The term $E(\omega)$ is the frequency-dependent out-of-plane excitability of a given mode, and can be obtained with (Wilcox et al., 2005):

$$
E(\omega)=\frac{i k(\omega) \omega}{8}\left(\frac{u_{\text {out }}(\omega)^{2}}{P_{z}(\omega)}\right)
$$

where $P_{z}(\omega)$ is the total power flow in the $z$-direction associated with the mode-shape as a function of the angular frequency, and $u_{\text {out }}(\omega)$ is the out-of-plane displacement on the surface of the mode-shape (at the position of excitation) as a function of the angular frequency. The dispersion curves of the waveguide $\left(k, P_{z}\right.$ and $\left.u_{\text {out }}\right)$ were obtained by solving the SAFE equations using the partial differential equation package in the Comsol Multiphysics and Matlab LiveLink environment. The complete time domain signal $u_{\text {sum }}(t)$ can then be 
obtained with the linear superposition of $n$ modes supported by the waveguide by:

$$
u_{\text {sum }}(t)=\sum_{m=1}^{n} u^{m}(t)
$$

where $u^{m}(t)$ is the surface out-of-plane displacement associated with the $m$-th mode and $n$ is the total number of modes supported by the waveguide. The advantage of the SAFE method as compared to other simulation method such as 3D FE modeling is that with SAFE, only the cross-section is modeled and meshed, resulting in computationally efficient simulations, which may represent a significant gain of computation time. Furthermore, the dispersion curves are only calculated once using the SAFE method and then a number of time domain signals can be generated within minutes at minimal computational cost. The equivalent simulation using 3D FE would take hours, if not days, and use many times more memory (Pereira et al., 2017).

The SAFE method can be considered as an accurate tool for simulating the ultrasonic guided wave response. The method has shown results in agreement with the 3D conventional FE simulations, as presented in our previous study (Pereira et al., 2017). However, SAFE has the advantage of requiring reduced computing resources (e.g. $5.5 \mathrm{~h}$ and $2.5 \mathrm{~Gb}$ of memory against $4 \mathrm{~h}$ and $1.4 \mathrm{~Gb}$ of memory for the FE and SAFE methods receptively). Even though the advantages of SAFE in terms of resource requirements are modest, it is worth noticing that once the dispersion curves are calculated, the propagated responses can be computed for different excitation configurations without running the simulations again within seconds at minimal memory cost $(<500 \mathrm{Mb})$. 


\section{B. Axial transmission configuration}

The axial transmission configuration was modeled using the SAFE procedure described above. The waveguide consists of a 2D multilayer model composed of a viscoelastic heterogeneous solid layer surrounded by two viscoelastic homogeneous fluids. The solid layer corresponds to the cortical bone while the two fluids correspond respectively to bone marrow and soft tissues. Because of the characteristics of the SAFE simulations, the multilayer 2D medium is assumed to have an infinite length along the axial direction, resulting in a 3D equivalent medium, as shown in Fig.1.

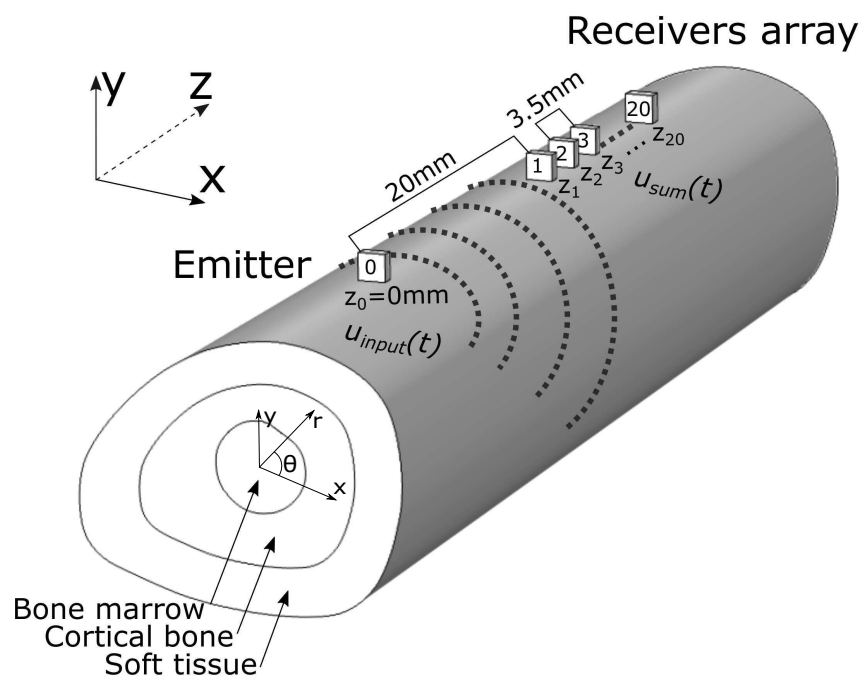

FIG. 1. Schematic of the equivalent 3D axial transmission configuration used to perform the SAFE simulations.

The acoustic excitation was performed using a point source located in a plane denoted $z_{0}=0 \mathrm{~mm}$ in contact with the upper part of the periosteal region of the bone cross-section. A 5-cycle Hann windowed toneburst centered at different frequencies between $20-85 \mathrm{kHz}$ was used as the input waveform to perform the excitation. Eight different excitation positions 
around the circumference of the cortical bone were investigated in this study. The positions, identified with the letters "A" to "H" in Fig. 2, were chosen based on the anatomical accessibility of a probe in a left human forearm. As a limitation of our study, the simulation of the excitability curves was made based on the displacement computed directly on the cortical bone tissue instead of on the overlaying soft tissue (see Fig. 2). The reason for this simplification is due to the higher mesh stability by considering the displacement in the inner elements (cortical tissue) instead of in the outer elements (soft tissue). When considering the displacement on the cortical bone tissue instead of the overlying soft tissue, a negligible change in the excitability curves was observed. However, for modes traveling with most of the energy in the cortical layer (which is the case for the majority of modes investigated in this study), the effect of this assumption on the excitability curves is acceptable. As the wavelengths of the modes of interest are long relative to the soft tissue thickness, a very limited number of modes are traveling with significant energy in the soft tissue. For the modes traveling in the cortical layer, the excitability curves have shown similar shape for both cases so as the relative difference and the rank between modes remained the same. As a consequence, no significant change on the relative variation obtained for the phase velocity and cut-off frequencies in the sensitivity study was observed with or without the soft tissue."

In reception, the out-of-plane displacement of the propagating waves were simulated at 20 positions $(\# 1, \# 2, \# 3 \ldots \# 20$ in Fig. 1 ), denoting an array of 20 receivers. The acquisition array was rotated in accordance with the excitation position around the circumference in order to keep the emitter and the receivers aligned. The acquisition elements were separated 


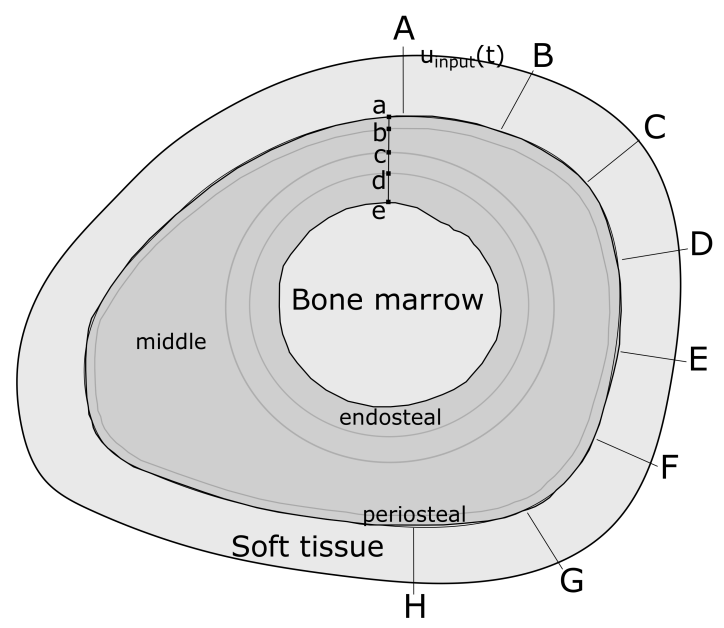

FIG. 2. Cross-section of the middle of the radius bone used for the SAFE analysis. Different regions were defined along the radial direction: periosteal (a-b), middle (b-c) and endosteal (d-e) regions. The letters "A" to "H" show the eight different positions used to perform the excitation on the bone surface.

from one another by a distance of $3.5 \mathrm{~mm}$, while varied from $z=20 \mathrm{~mm}$ to $z=90 \mathrm{~mm}$. The signals obtained were processed using the 2D-FFT (Alleyne and Cawley, 1990) in order to calculate the frequency vs. phase-velocity diagram. Figure 3a shows typical received time domain signals obtained for an excitation frequency centered at $45 \mathrm{kHz}$. Figure 3b shows the frequency vs. phase-velocity diagram obtained after performing the 2D-FFT.

For each diagram, the phase velocity of the low-order mode (named $V_{p h}$ ) was measured by taking the peak of energy at the central frequency of the excitation waveform, as shown in the black square in Fig. 3b. Similarly, the cut-off frequency of the higher-order mode (named $F_{c u t-o f f}$ ) was measured by taking the peak of energy at a reference velocity equal to $4000 \mathrm{~m} / \mathrm{s}$ (see black circle in Fig. $3 \mathrm{~b})$. Those two features $\left(V_{p h}\right.$ and $\left.F_{\text {cut-off }}\right)$ were used to evaluate the performance of each configuration in term of assessing the variations in the intracortical bone properties. 

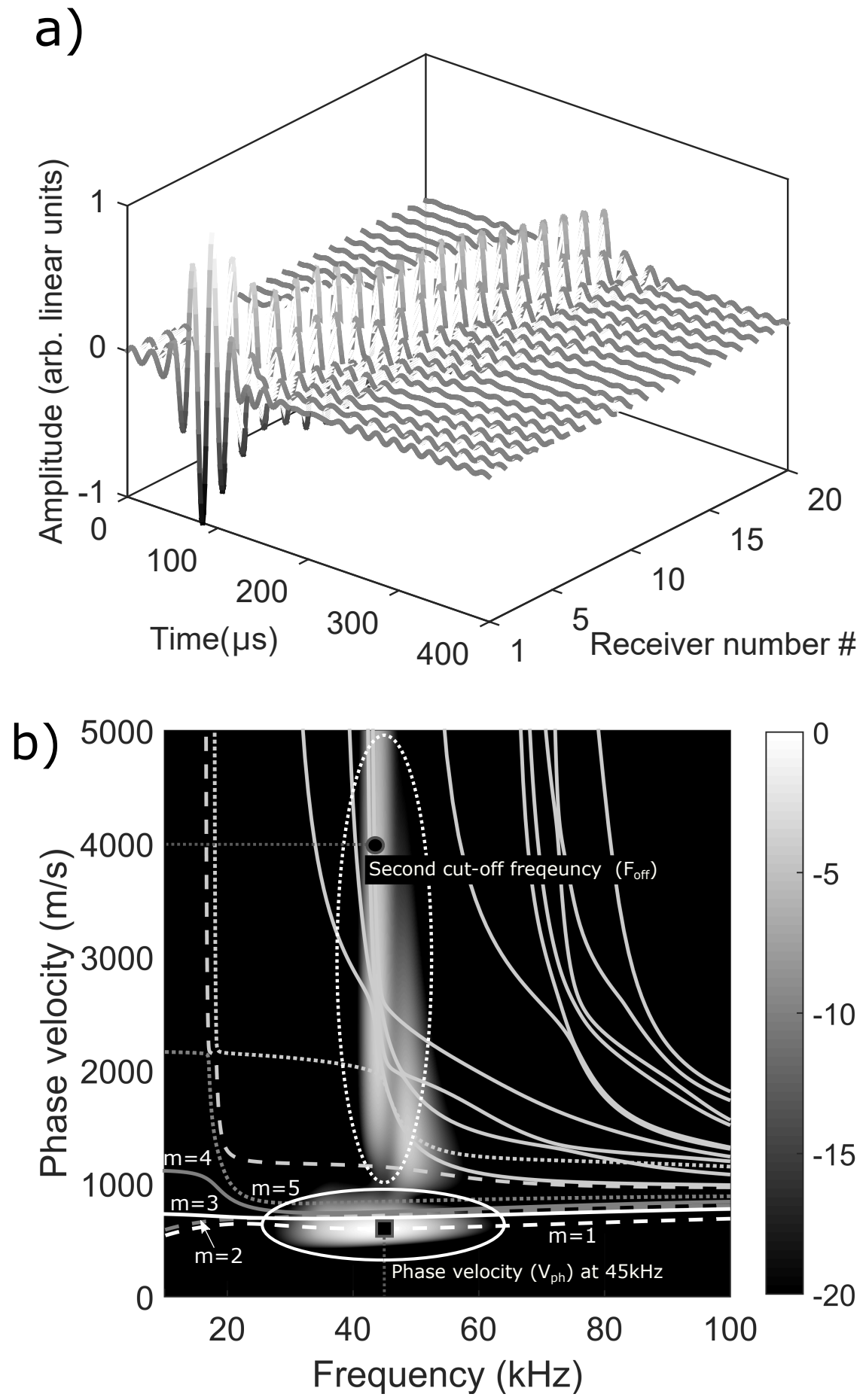

FIG. 3. a) Simulated time domain signals obtained at each receiving position. b) Typical phase velocity vs. frequency diagram showing the intensity of the excited modes (dB scale) and the measured phase velocity $V_{p h}$ and cut-off frequency $F_{c u t-o f f}$. 
It should be noted that the $2 \mathrm{D}$ tri-layer model investigated is this study did not account for the impacts of structural or geometrical irregularities along the axial direction since the waveguide was assumed to be constant and infinite. Such an assumption may change the signal of guided waves propagation in bone tissue. However, this limitation is balanced by the fact that the bone properties are typically measured in the central region of the bone, where the assumption of a constant profile along the axial direction holds because of the long wavelength in the frequency range used in this study.

\section{Modeling cortical bone}

The geometry of the waveguide was extracted from a slice of a human radius geometry. The radius geometry was provided by Sawbones (Sawbone, 1997), and was built based on $\mu \mathrm{CT}$ images of the human radius. In this work, the middle third region, which is composed only of cortical bone, was used. Moreover, bone-marrow was added inside the cortical shell, and a $3.5 \mathrm{~mm}$ layer of soft-tissue was added outer the cortical shell. The tri-layer crosssection was imported into the COMSOL Multiphysics environment for execution of the SAFE analysis. The mesh was built using triangular elements with a maximum size of 0.5 $\mathrm{mm}$, subject to a constraint of at least 15 elements per wavelength. The bone marrow and soft tissue were modeled as homogeneous viscoelastic fluids with the same properties used by Naili et al.(Naili et al., 2010) (bulk modulus=2.25e9 Pa, bulk viscosity=1.97 Pa.s and density $=1000 \mathrm{~kg} / \mathrm{m}^{3}$ ), while the cortical bone was modeled as a viscoelastic transversally isotropic material. Furthermore, cortical bone was divided into three regions along the radial direction: periosteal (a-b), middle (b-c) and endosteal (d-e) regions (see Fig. 2a). Each 
TABLE I. Summary of the properties used to model cortical bone. The real part of the stiffness coefficients were adapted from the experimental results obtained by (Sansalone et al., 2010), while the imaginary parts were adapted from the results presented by (Naili et al., 2010), using equation 7 .

\begin{tabular}{|c|c|c|c|c|}
\hline \multirow{2}{*}{$\begin{array}{l}\text { Viscoelastic } \\
\text { coefficient** }\end{array}$} & \multirow{2}{*}{$\begin{array}{l}\text { Periosteal } \\
\text { (a-b) }\end{array}$} & \multirow{2}{*}{$\begin{array}{l}\text { Middle } \\
\text { (b-c) }\end{array}$} & \multicolumn{2}{|c|}{ Endosteal } \\
\hline & & & Healthy $\left(\mathrm{d}^{*}-\mathrm{e}^{*}\right)$ & Osteoporotic (d-e) $)^{* *}$ \\
\hline$C_{11}(\mathrm{~Pa})$ & $13.17 \mathrm{e} 9+94.95 f i$ & $11.46 \mathrm{e} 9+82.62 f i$ & $4.78 \mathrm{e} 9+34.46 f i$ & $3.11 \mathrm{e} 9+22.42 f i$ \\
\hline$C_{13}(\mathrm{~Pa})$ & $6.60 \mathrm{e} 9+91.74 f i$ & $6.03 \mathrm{e} 9+83.81 f i$ & $3.32 \mathrm{e} 9+46.14 f i$ & $2.65 \mathrm{e} 9+36.83 f i$ \\
\hline$C_{33}(\mathrm{~Pa})$ & $16.04 \mathrm{e} 9+109.2 f i$ & $14.31 \mathrm{e} 9+97.45 f i$ & $6.19 \mathrm{e} 9+42.15 f i$ & $4.17 \mathrm{e} 9+28.39 f i$ \\
\hline$C_{44}(\mathrm{~Pa})$ & $3.75 \mathrm{e} 9+14.70 f i$ & $3.15 \mathrm{e} 9+12.34 f i$ & $0.87 \mathrm{e} 9+3.41 f i$ & $0.30 \mathrm{e} 9+1.17 f i$ \\
\hline$C_{66}(\mathrm{~Pa})$ & $3.62 \mathrm{e} 9+14.19 f i$ & $2.99 \mathrm{e} 9+11.72 f i$ & $0.78 \mathrm{e} 9+3.05 f i$ & $0.23 \mathrm{e} 9+0.90 f i$ \\
\hline Density $\left(\mathrm{kg} / \mathrm{m}^{3}\right)$ & 1850.00 & 1850.00 & 1299.04 & 1161.30 \\
\hline
\end{tabular}

*The "Healthy" conditions were defined based on an arbitrary gain of $20 \%$ on the value of all stiffness coefficients and density. ${ }^{* *}$ Adapted from the experimental results obtained by Sansalone et al. (Sansalone et al., 2010)

region was defined with different values for the transversally isotropic stiffness coefficients and density $\left(C_{11}, C_{13}, C_{33}, C_{44}, C_{66}\right.$ and $\left.\rho\right)$, as summarized in Table I. The value of each region was chosen based on a simplification of experimental results reported by Sansalone et al. (Sansalone et al., 2010). A more detailed description of the distribution of the material properties along the radial direction is provided in the following section. 
In the viscoelastic model used in this study, the elastic stiffness constants were written as complex numbers:

$$
C_{c}=C_{c}+\eta_{c} f i
$$

where the subscripts $c=11,13,33,44$ and 66 , and $f$ corresponds to the frequency. The real part of the stiffness constants is assumed to be independent of the frequency, while the imaginary part results from the use of the linear theory of viscoelasticity, assuming frequency-dependent losses in the waveguide. Because relevant data was lacking, the viscosity coefficients $\eta_{11}, \eta_{13}, \eta_{33}, \eta_{44}$ and $\eta_{66}$ shown in Table 1 were defined based on the viscosity coefficients found in the literature. The coefficients reported in (Naili et al., 2010) were adjusted by the ratio between the elastic coefficients used in this study and those reported in (Naili et al., 2010), as given by:

$$
\eta_{c}=\frac{C_{c}}{C_{c}^{*}} \cdot \eta_{c}^{*}
$$

where the subscripts $c=11,13,33,44$ and $66, \eta_{c}^{*}$ and $C_{c}^{*}$ are respectively the viscosity and elastic coefficients reported by Nailiet al. (Naili et al., 2010) for the cortical bone.

\section{Heterogeneous distribution of bone properties}

The heterogeneous nature of the biomechanical properties of cortical bone tissue was adapted from the experimental results obtained by Sansalone et al. (Sansalone et al., 2010) using 3-D synchrotron micro-computed tomography images. In order to simplify the spatial distribution of each material property, the original values (Fig. 4) were adapted by choosing three different constant values for the periosteal (between a-b), middle (between b-c) and 
endosteal (between d-e) regions. Moreover, a linear variation was assumed in the region between the middle and periosteal bone (between c-d). For the density, the same approach was applied based on porosity distribution reported in the study. The conversion was made considering a scale where $100 \% \mathrm{BV} / \mathrm{TV}$ (bone volume/ total volume) denotes a bone with a $1850 \mathrm{~kg} / \mathrm{m}^{3}$ density and $0 \%$ of $\mathrm{BV} / \mathrm{TV}$ denotes only bone marrow with a $1000 \mathrm{~kg} / \mathrm{m}^{3}$ density. The constant values, as well as the linear variation of each material property, were chosen to minimize the gap between the original (Sansalone et al., 2010) and simplified values. Figure 4 shows the original and simplified (healthy and osteoporotic) distributions for the coefficient $C_{11}$.

Two different physiopathological conditions, namely "Healthy" and "Osteoporotic", were defined for the endosteal region (between $\mathrm{d}^{*} \mathrm{e}^{*}$ and d-e in Fig. 4, respectively). The "Osteoporotic" condition was defined with the simplified distribution taken from the original data (Sansalone et al., 2010). This assumption was made because the data were obtained from an osteoporotic 79-year old patient. The "Healthy" condition was then obtained by: i) arbitrarily increasing the values of all stiffness coefficients and density in the endosteal region by $20 \%$, and ii) by reducing the length of the endosteal region by $20 \%$.

As a limitation, the approach used to model the "Healthy" condition constitutes a simple way of modeling a slightly less degraded condition, which does not necessarily represents the condition associated with a healthy patient. However, since the properties are changing only in the endosteal in our sensitivity study, the magnitude of change between the "Healthy" and "Osteoporotic" condition can be considered very small, which may be similar to the magnitude of degradation associated to the early-stage osteoporosis. Furthermore, the het- 


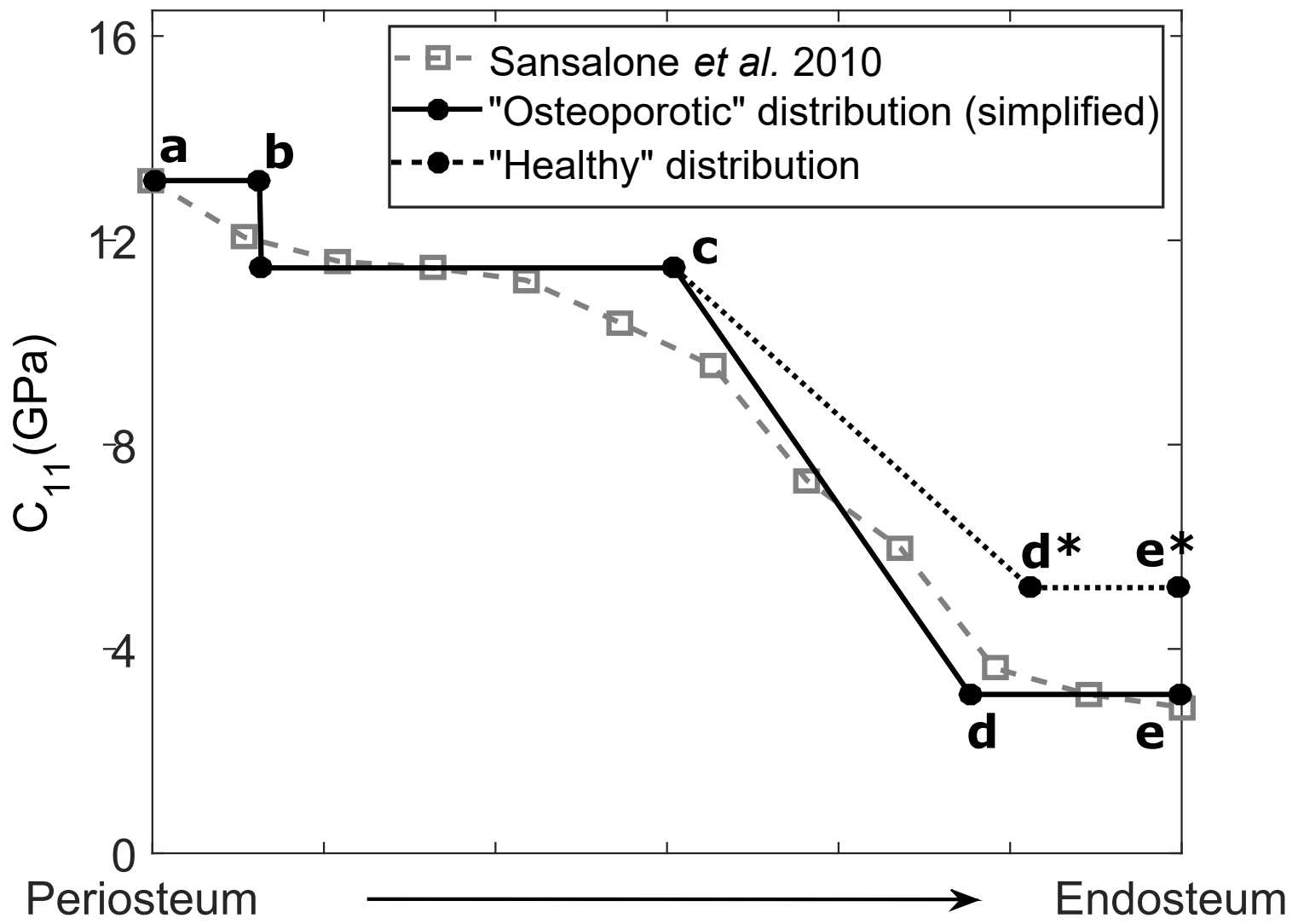

FIG. 4. Simplified distribution of the elastic coefficients and density varying with the distance from the periosteum for the healthy and osteoporotic condition.

erogeneous nature of cortical bone is based on homogenized local material properties, which are not easy to define due to the multi-scale nature of bone and its dependence on the microstructure at smaller scales. However, such discrepancies tend to be minimized by using low-frequency excitation associated with long wavelengths of the excited modes. Table I shows a summary of the "Healthy" and "Osteoporotic" elastic coefficients and densities used to defined the aforementioned scenarios. 


\section{RESULTS AND DISCUSSION}

\section{Effect of excitation position}

Figures $5 \mathrm{a}$ to $\mathrm{h}$ show the normalized excitability curves (in the $10-100 \mathrm{kHz}$ range) for an excitation performed at eight different positions on the bone surface (identified with letters "A" to "H" in Fig. 2). The normalized excitability predicts the relative amplitude expected to be observed by a receiver when an emitter at position "A" applies a load in the radial direction (see Fig. 2). The curves show the modal excitability of five modes with similar velocities $(\mathrm{m}=1, \mathrm{~m}=2, \mathrm{~m}=3, \mathrm{~m}=4$, and $\mathrm{m}=5$, marked with a solid line ellipse in Fig. 3). A notable difference in the modal excitability can be observed between each configuration, which is expected for non-symmetric waveguides such as the bone geometry modeled in this study. For practical applications, a position that can mainly excite a single mode is preferable in order to avoid interferences from other modes.

The modes $\mathrm{m}=1, \mathrm{~m}=2, \mathrm{~m}=3, \mathrm{~m}=4$, and $\mathrm{m}=5$ all present flexural-like mode shapes. For instance, Fig. 6a and 6b show the out-of-plane component of the fundamental flexural tube mode $\mathrm{F}(1,1)$ and mode shape of $\mathrm{m}=1$ respectively. Despite the similarities between the displacement fields and the mode order, a direct association to the mode shape of tubular waveguides is not possible due to the non-symmetric nature of the waveguide and its arbitrary geometry

The modes $\mathrm{m}=1, \mathrm{~m}=2$, and $\mathrm{m}=3$ all show an excitability $10 \mathrm{~dB}$ higher than the other modes, as shown in the highlighted regions in Fig. 3a, 3c, and 3h, respectively. Furthermore, according to Figure 7 , the modes $\mathrm{m}=1, \mathrm{~m}=2$, and $\mathrm{m}=3$ have a higher percentage of the total 

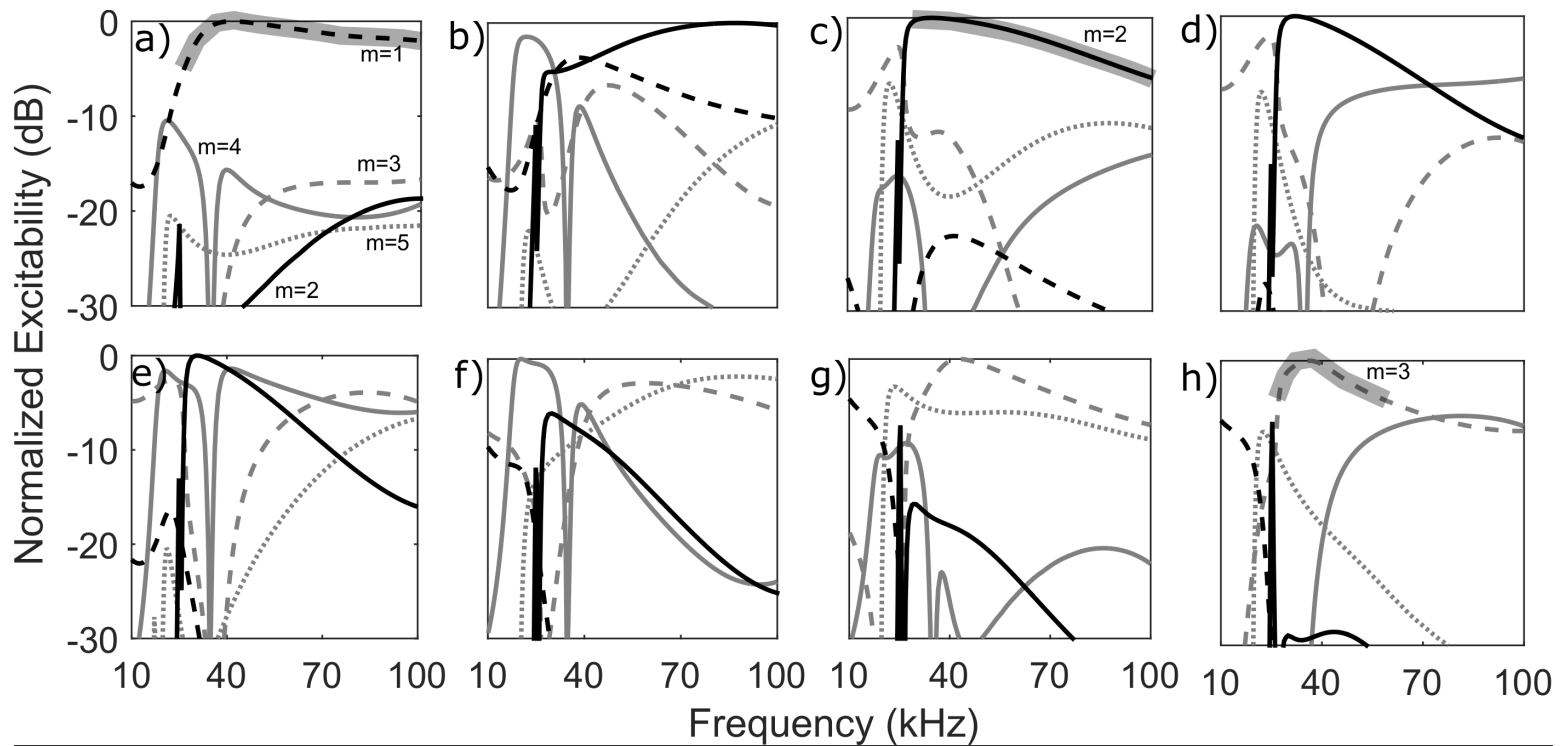

FIG. 5. Normalized modal excitability obtained for the excitation performed at eight different position on the bone surface from $10 \mathrm{kHz}$ to $100 \mathrm{kHz}$. The letters a) to h) are associated to the excitation position "A" to "H" shown in Fig. 2, respectively.

power flow concentrated in the endosteal region as compared to the other modes, which indicates that they are likely to be sensitive to changes in this region. Thus, the excitation at position "A", "C" and "H" were chosen as the most suitable positions to excite a dominant mode; they were therefore further investigated in this paper. Since the attenuation of the modes is expected to be small at very low frequencies $(<100 \mathrm{kHz})$, it was not taken into account to choose the most suitable excitation and detection positions

\section{Effect of physiopathological conditions}

Table II shows the percentage variation in the phase velocity $\left(V_{p h}\right)$ and cut-off frequency $\left(F_{c u t-o f f}\right)$ for the excitation performed at position "A", "C" and "H". The variations was calculated based on the difference computed between the two physiopathological conditions 


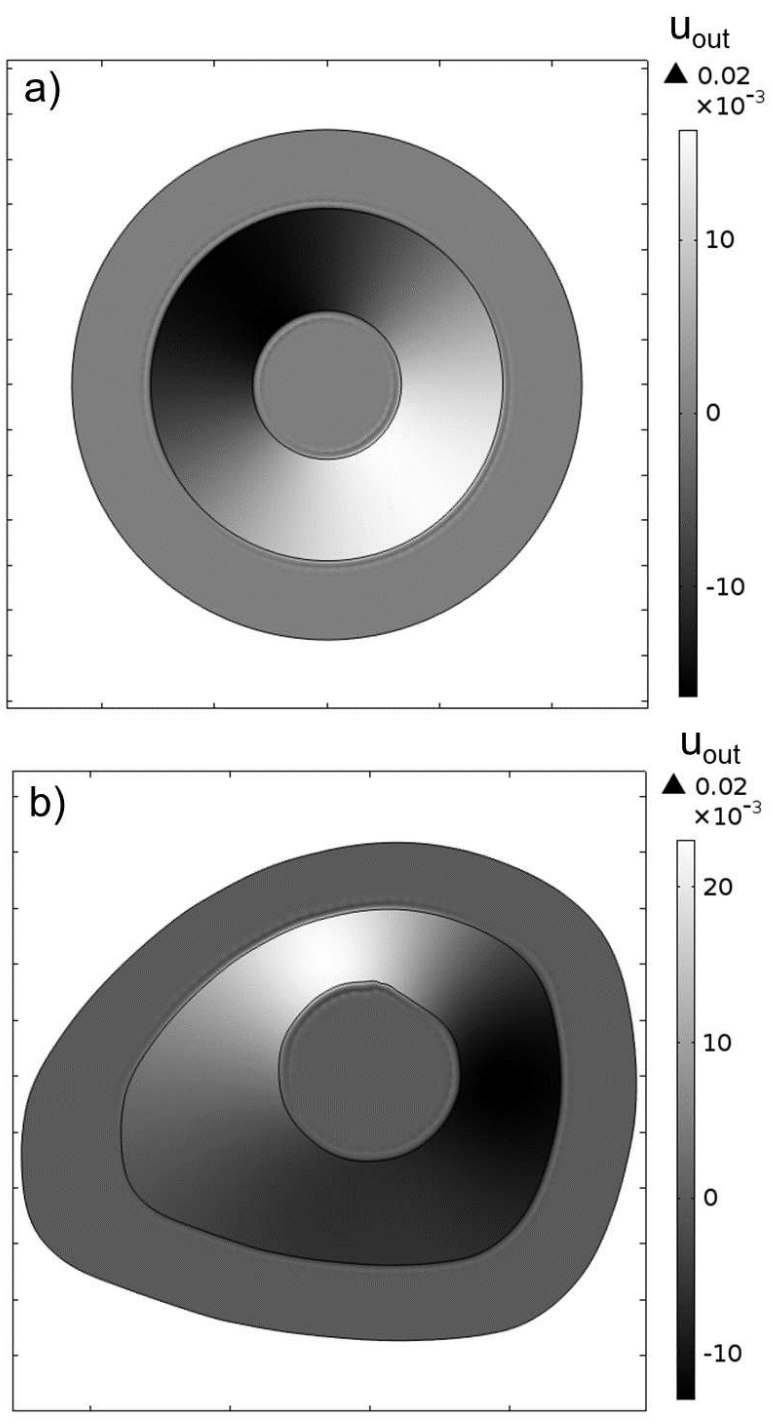

FIG. 6. Out-of-plane displacement field (radial direction $r$ in Fig. 1) at $40 \mathrm{kHz}$ for: a) fundamental flexural mode $\mathrm{F}(1,1)$ on a tubular geometry waveguide and $\mathrm{b}$ ) mode $\mathrm{m}=1$ on a bone-like geometry waveguide.

("Healthy" and "Osteoporotic"). The simulations were performed using input waveforms centered at different frequencies between $20-85 \mathrm{kHz}$. This choice was made in order to cover a frequency range that has the potential to excite separately one of the five modes with similar velocities on the excitability curves in Fig. 5. 
TABLE II. Total variation of the phase velocity $V_{p h}$ and cut-off frequency $F_{c u t-o f f}$ for the excitations performed at position "A", "C" and "H".

\begin{tabular}{|c|c|c|c|}
\hline \multirow{2}{*}{$\begin{array}{c}\text { Phase velocity }\left(V_{p h}\right) \text { variation }(\%) \\
35 \mathrm{kHz}\end{array}$} & \multicolumn{3}{|c|}{ Position A Position C Position H } \\
\hline & 5.59 & 4.91 & 4.21 \\
\hline $45 \mathrm{kHz}$ & 7.98 & 6.01 & 4.23 \\
\hline $55 \mathrm{kHz}$ & 7.36 & 6.23 & 4.03 \\
\hline $65 \mathrm{kHz}$ & 6.72 & 5.44 & 2.18 \\
\hline $75 \mathrm{kHz}$ & 6.21 & 4.99 & 2.50 \\
\hline $85 \mathrm{kHz}$ & 5.99 & 4.48 & 2.07 \\
\hline
\end{tabular}

Cut-off frequency $\left(F_{c u t-o f f}\right)$ variation $(\%)$ Position A Position C Position H

\begin{tabular}{cccc}
\hline First cut-off frequency $(20 \mathrm{kHz})$ & 17.37 & 16.31 & 16.31 \\
Second cut-off frequency $(40 \mathrm{kHz})$ & 9.42 & 12.15 & 11.23 \\
Third cut-off frequency $(70 \mathrm{kHz})$ & 5.45 & 6.99 & 5.38 \\
\hline
\end{tabular}

*The variations were calculated based on the difference computed between the "Healthy" and the

"Osteoporotic" condition.

The sensitivity of phase velocity $\left(V_{p h}\right)$ was strongly affected by the excitation position.

The highest sensitivity was achieved at position "A", for all frequencies. On the other hand, the cut-off frequency $\left(F_{\text {cut-off }}\right)$ was only slightly affected by the position of excitation, showing similar sensitivities for all positions. However, the cut-off frequency was strongly 
affected by the frequency of excitation, showing a significantly higher sensitivity at the first cut-off frequency $(20 \mathrm{kHz})$ as compared to the second $(40 \mathrm{kHz})$ and third $(70 \mathrm{kHz})$. Similarly, an increase in the sensitivity of the phase velocity $\left(V_{p h}\right)$ was observed at lower frequencies, reaching a maximum variation at $45 \mathrm{kHz}$, for all positions.

Figure 7 shows the power flow in the endosteal region (normalized to the total power flow) for modes $\mathrm{m}=1, \mathrm{~m}=2, \mathrm{~m}=3, \mathrm{~m}=4$, and $\mathrm{m}=5$, varying from $20 \mathrm{kHz}$ to $100 \mathrm{kHz}$. The results show that mode $m=1$ has a higher power flow in the endosteal region as compared to the other modes, achieving approximately $23 \%$ of the total power in this region at $45 \mathrm{kHz}$. This explains the higher sensitivity obtained for the excitation performed at position "A", in which the mode $\mathrm{m}=1$ excitability is $15 \mathrm{~dB}$ higher than the other modes (see Fig. 5a)

\section{Effect of stiffness coefficients and density}

Table III shows the percentage variation computed for the $V_{p h}$ and $F_{c u t-o f f}$ for each viscoelastic coefficient and density separately. The condition varied from "Healthy" to the "Osteoporotic". The excitation was performed at position "A" using central frequencies ranging between $20-85 \mathrm{kHz}$.

The sensitivity of $V_{p h}$ showed a positive variation associated with coefficients $C_{11}, C_{33}$, $C_{44}, C_{66}$, while a negative variation was associated with the coefficient $C_{13}$ and the density. Coefficient $C_{44}$ showed the major contribution for most of the frequencies investigated (except at $35 \mathrm{kHz}$ ), accounting for approximately $50 \%$ of the variations in the degradation of all parameters taken together (identified as "Overall" in Table III). The reduction in sensitivity observed at $35 \mathrm{kHz}$ was found to be associated with the sharp decrease in the power flow of 


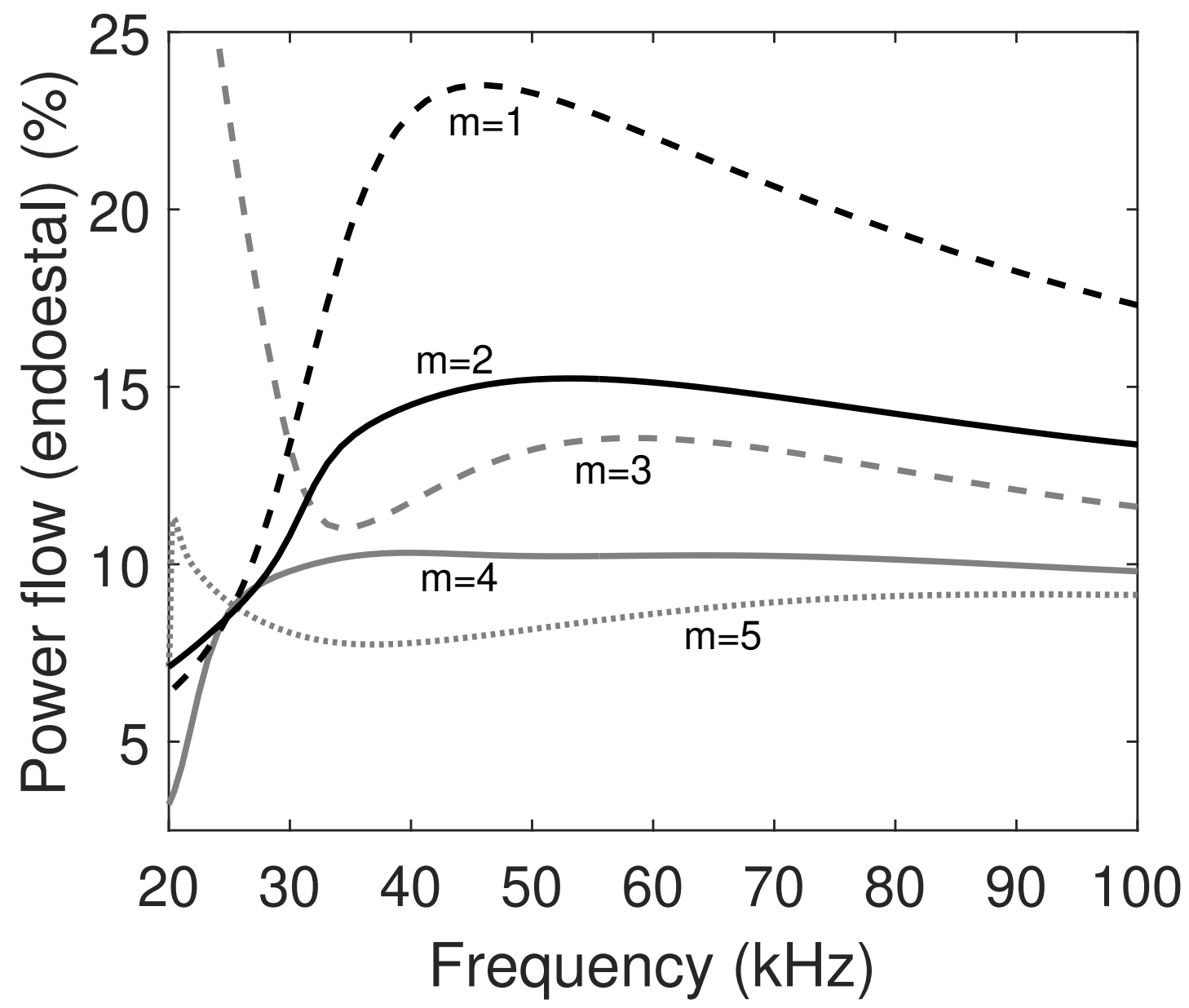

FIG. 7. Power flow in the endosteal region normalized by the total power flow for modes $\mathrm{m}=1, \mathrm{~m}=2$, $\mathrm{m}=3, \mathrm{~m}=4$, and $\mathrm{m}=5$ from $20 \mathrm{kHz}$ to $100 \mathrm{kHz}$.

mode $\mathrm{m}=1$ seen in Fig. 7 at frequencies below $45 \mathrm{kHz}$. In addition, it may be related to the reduction in excitability seen in mode $\mathrm{m}=1$ at lower frequencies (see the excitability curves in Fig. 5a), which may increase the interference from other modes, and consequently, reduce the sensitivity. 
TABLE III. Percentage variation computed for $V_{p h}$ and $F_{c u t-o f f}$ for each viscoelastic coefficient and density separately.

\begin{tabular}{|c|c|c|c|c|c|c|}
\hline \multirow[b]{2}{*}{ Phase velocity $\left(V_{p h}\right)$ variation $(\%)$} & \multicolumn{6}{|c|}{ Position A } \\
\hline & $C_{11} \quad C_{13}$ & $C_{33}$ & $C_{44}$ & $C_{66}$ & Density & Overall \\
\hline $35 \mathrm{kHz}$ & $0.32-1.42$ & 0.8 & 1.30 & 1.63 & -0.79 & 5.59 \\
\hline $45 \mathrm{kHz}$ & $0.37-1.45$ & 1.24 & 3.30 & 2.01 & -0.611 & 7.98 \\
\hline $55 \mathrm{kHz}$ & $0.31-2.23$ & 1.47 & 3.21 & 0.31 & -0.72 & 7.36 \\
\hline $65 \mathrm{kHz}$ & $0.36-2.02$ & 1.73 & 3.25 & 0.36 & -0.62 & 6.72 \\
\hline $75 \mathrm{kHz}$ & $0.16-1.73$ & 1.54 & 3.25 & 0.32 & -0.71 & 6.21 \\
\hline $85 \mathrm{kHz}$ & $0.08-1.14$ & 1.20 & 3.21 & 0.42 & -0.67 & 5.99 \\
\hline
\end{tabular}

Cut-off frequency $\left(F_{\text {cut-off }}\right)$ variation $(\%)$

$\begin{array}{lccccccc}\text { First cut-off frequency }(20 \mathrm{kHz}) & 0 & 0 & 0 & 0 & 22.06 & -2.34 & 17.37 \\ \text { Second cut-off frequency }(40 \mathrm{kHz}) & 0 & 0 & 0.90 & 0.90 & 9.42 & -0.90 & 9.42 \\ \text { Third cut-off frequency }(70 \mathrm{kHz}) & 0.94 & 0.52 & 0.41 & 0.94 & 3.98 & -1.05 & 5.45\end{array}$

For the sensitivity of $F_{\text {cut-off }}$, a positive variation associated with the coefficient $C_{66}$ was observed, accounting for almost $100 \%$ of the "Overall" variation. Such a dependence could be used to assess the status of coefficient $C_{66}$ separately. 


\section{CONCLUSION}

In this paper, the SAFE method was used to simulate the propagation of guided waves at low frequency $(20-85 \mathrm{kHz})$ in a bone waveguide in the context of an axial transmission configuration. The SAFE method was shown to be an efficient tool for investigating the effect of intracortical properties on the propagation of guided waves since a number of configurations were simulated using reduced computing resources.

Considering the actual bone geometry, sixteen guided wave modes were found in the 10$100 \mathrm{kHz}$ frequency range (Figure 3b). However, only some of the modes have shown enough excitability and consequently clinical interest. In addition, the excitability and sensitivity of each mode were shown to vary according to the frequency and position of excitation on the bone surface. The phase velocity showed a maximum sensitivity at $45 \mathrm{kHz}$, which would appear to be associated with the peak of energy (power flow) concentrated in the endosteal region at this frequency. The cut-off frequency was only slightly affected by the position of excitation, but strongly by the frequency of excitation. A maximum sensitivity was achieved for the first cut-off frequency at approximately $20 \mathrm{kHz}$.

The sensitivity of phase velocity was associated with the variation in the physiopathological conditions of all the coefficients and density, but mainly with $C_{44}$. The sensitivity of the cut-off frequency for its part was mainly associated with variation in the physiopathological conditions of the stiffness coefficient $C_{66}$, allowing the axial shear modulus to be assessed separately. 
Thus, by selecting an adequate frequency and position of excitation, the low-frequency axial transmission was shown to be a promising method for assessing intracortical bone properties. The features identified in this study could be used as a metric to compare the similarity between experimental and numerical data. A cost function based on these features could then be implemented into an inversion scheme to retrieve reliable bone properties from experimental data at low frequency. A parameterized bone-like geometry model, instead of a plate or cylinder, could potentially reduce the errors commonly encountered with in-vivo and ex-vivo experiments. For instance, the model could potentially compensate geometrical variations between different patients that are unrelated to the bone quality, such as the outer diameter and the external shape of the bone. The method could, therefore, be applied to identify small changes associated with early-stage osteoporosis or gradual evolution of the bone condition over time. For these extreme cases, since the sensitivity associated to slightly different degraded conditions was found modest, a good basis for comparison (e.g., a baseline method or a large reference database) would have to be implemented in order to guarantee the robustness of the method.

\section{ACKNOWLEDGMENTS}

This work was developed in collaboration with the Centre de recherche l'Hôpital du Sacré-Coeur de Montréal and École de technologie supérieure. The authors acknowledge the grant from the Fonds d'Internationalisation de la Recherche (FIR) of École de technologie supérieure. 


\section{REFERENCES}

Alleyne, D. N., and Cawley, P. (1990). "A 2-dimensional fourier transform method for the quantitative measurement of lamb modes," in Ultrasonics Symposium, 1990. Proceedings., IEEE 1990, IEEE, 45 Hoes Lane Piscataway, NJ 08854-4141 USA, pp. 1143-1146 vol.2, doi: 10.1109/ULTSYM. 1990.171541.

Bossy, E., Talmant, M., and Laugier, P. (2004). "Three-dimensional simulations of ultrasonic axial transmission velocity measurement on cortical bone models," The Journal of the Acoustical Society of America 115(5).

Chen, J., and Su, Z. (2014). "On ultrasound waves guided by bones with coupled soft tissues: A mechanism study and in vitro calibration," Ultrasonics 54(5), 1186 - 1196, http: //www.sciencedirect.com/science/article/pii/S0041624X13002242, doi: https:// doi.org/10.1016/j.ultras.2013.08.002.

Consensus development conference: prophylaxis and treatment of osteoporosis (1991)., 90, pp. $107-110$.

Egorov, V., Tatarinov, A., Sarvazyan, N., Wood, R., Magidenko, L., Amin, S., Khosla, S., Ruh, R. J., Ruh, J. M., and Sarvazyan, A. (2014). "Osteoporosis detection in postmenopausal women using axial transmission multi-frequency bone ultrasonometer: Clinical findings," Ultrasonics 54(5), 1170 - 1177, http://www.sciencedirect.com/science/ article/pii/S0041624X1300259X, doi: https://doi.org/10.1016/j.ultras.2013. 08.017. 
Fan, Z., Lowe, M. J. S., Castaings, M., and Bacon, C. (2008). "Torsional waves propagation along a waveguide of arbitrary cross section immersed in a perfect fluid," The Journal of the Acoustical Society of America 124(4), 2002-2010, https://doi.org/10.1121/1. 2968677, doi: 10.1121/1.2968677.

Foiret, J., Minonzio, J., Chappard, C., Talmant, M., and Laugier, P. (2014). "Combined estimation of thickness and velocities using ultrasound guided waves: a pioneering study on in vitro cortical bone samples," IEEE Transactions on Ultrasonics, Ferroelectrics, and Frequency Control 61(9), 1478-1488, doi: 10.1109/TUFFC.2014.3062.

Giangregorio, L., Papaioannou, A., and Zytaruk, N. (2006). "Fragility fractures and the osteoporosis care gap: An international phenomenon," Seminars in Arthritis and Rheumatism 35(5), 293-305, doi: 10.1016/j.semarthrit.2005.11.001.

Gluer, C. (2008). "A new quality of bone ultrasound research," IEEE Transactions on Ultrasonics, Ferroelectrics, and Frequency Control 55(7), 1524-1528, doi: 10 .1109/TUFFC . 2008.828.

Gluer, C. C. (1997). "Quantitative ultrasound techniques for the assessment of osteoporosis: Expert agreement on current status," Journal of Bone and Mineral Research 12(8), 12801288, doi: 10.1359/jbmr.1997.12.8.1280.

Haïat, G., Naili, S., Grimal, Q., Talmant, M., Desceliers, C., and Soize, C. (2009). "Influence of a gradient of material properties on ultrasonic wave propagation in cortical bone: Application to axial transmission," The Journal of the Acoustical Society of America 125(6). Haba, Y., Skripitz, R., Lindner, T., Köckerling, M., Fritsche, A., Mittelmeier, W., and Bader, R. (2016). "Bone mineral densities and mechanical properties of retrieved femoral 
bone samples in relation to bone mineral densities measured in the respective patients," The Scientific World Journal 2012.

Haiat, G., Naili, S., Ba Vu, M., Desceliers, C., and Soize, C. (2011). "Equivalent contributing depth investigated by a lateral wave with axial transmission in viscoelastic cortical bone," The Journal of the Acoustical Society of America 129(4).

Kanis, J. A. (1994). "Assessment of fracture risk and its application to screening for postmenopausal osteoporosis: Synopsis of a who report," Osteoporosis International 4(6), 368381, doi: 10.1007/BF01622200.

Kassou, K., Remram, Y., Laugier, P., and Minonzio, J.-G. (2017). "Dispersion characteristics of the flexural wave assessed using low frequency (50-150khz) point-contact transducers: A feasibility study on bone-mimicking phantoms," Ultrasonics $\mathbf{8 1}$, 1—9, https: //doi.org/10.1016/j.ultras.2017.05.008, doi: 10.1016/j.ultras.2017.05.008.

Kaufman, J. J., and Einhorn, T. A. (1993). "Perspectives: Ultrasound assessment of bone," Journal of Bone and Mineral Research 8(5), 517-525, doi: 10.1002/jbmr.5650080502.

Kilappa, V., Moilanen, P., Salmi, A., Haeggström, E., Zhao, Z., Myllylä, R., and Timonen, J. (2015). "Tailoring the excitation of fundamental flexural guide waves in coated bone by phase-delayed array: Two-dimensional simulations," The Journal of the Acoustical Society of America 137(3).

Kilappa, V., Moilanen, P., Xu, L., Nicholson, P. H. F., Timonen, J., and Cheng, S. (2011). "Low-frequency axial ultrasound velocity correlates with bone mineral density and cortical thickness in the radius and tibia in pre- and postmenopausal women," Osteoporosis International 22(4), 1103-1113, doi: 10.1007/s00198-010-1273-7. 
Le, L. H. ., Gu, Y. J. ., Li, Y. ., and Zhang, C. . (2010). "Probing long bones with ultrasonic body waves," Applied Physics Letters 96(11), 114102, https://doi.org/10. 1063/1.3300474, doi: 10.1063/1.3300474.

Loveday, P. W. (2008). "Simulation of piezoelectric excitation of guided waves using waveguide finite elements," IEEE Transactions on Ultrasonics, Ferroelectrics, and Frequency Control 55(9), 2038-2045, doi: 10.1109/TUFFC. 895.

Minonzio, J.-G., Foiret, J., Moilanen, P., Pirhonen, J., Zhao, Z., Talmant, M., Timonen, J., and Laugier, P. (2015). "A free plate model can predict guided modes propagating in tubular bone-mimicking phantoms," The Journal of the Acoustical Society of America 137(1), EL98-EL104, https://doi.org/10.1121/1.4903920, doi: 10.1121/1.4903920.

Moilanen, P., Nicholson, P. H., Kilappa, V., Cheng, S., and Timonen, J. (2007). "Assessment of the cortical bone thickness using ultrasonic guided waves: Modelling and in vitro study," Ultrasound in Medicine \& Biology 33(2), 254 - 262, doi: http://dx.doi.org/10.1016/ j.ultrasmedbio.2006.07.038.

Moreau, L., Minonzio, J.-G., Talmant, M., and Laugier, P. (2014). "Measuring the wavenumber of guided modes in waveguides with linearly varying thickness," The Journal of the Acoustical Society of America 135(5), 2614-2624, https://doi.org/10.1121/1. 4869691, doi: 10.1121/1.4869691.

Muller, M., Moilanen, P., Bossy, E., Nicholson, P., Kilappa, V., Timonen, J., Talmant, M., Cheng, S., and Laugier, P. (2005). "Comparison of three ultrasonic axial transmission methods for bone assessment," Ultrasound in Medicine \& Biology 31(5), 633 - 642, doi: http://dx.doi.org/10.1016/j.ultrasmedbio.2005.02.001. 
Naili, S., Vu, M.-B., Grimal, Q., Talmant, M., Desceliers, C., Soize, C., and Haïat, G. (2010). "Influence of viscoelastic and viscous absorption on ultrasonic wave propagation in cortical bone: Application to axial transmission," The Journal of the Acoustical Society of America 127(4).

Nguyen, V.-H., and Naili, S. (2014). "Semi-analytical solution of transient plane waves transmitted through a transversely isotropic poroelastic plate immersed in fluid," Journal of Engineering Mathematics 86(1), 125-138, doi: 10.1007/s10665-013-9654-5.

Nguyen, V.-H., Tran, T. N. H. T., Sacchi, M. D., Naili, S., and Le, L. H. (2017). "Computing dispersion curves of elastic/viscoelastic transversely-isotropic bone plates coupled with soft tissue and marrow using semi-analytical finite element (safe) method," Computers in biology and medicine 87, 371-381, https://doi.org/10.1016/j.compbiomed.2017. 06.001, doi: 10.1016/j.compbiomed.2017.06.001.

Nicholson, P. H. F. (2008). "Ultrasound and the biomechanical competence of bone," IEEE Transactions on Ultrasonics, Ferroelectrics, and Frequency Control 55(7), 1539-1545, doi: 10.1109/TUFFC. 2008.830.

Office of the Surgeon General (2004). Bone Health and Osteoporosis (American Standards Association, US).

Papaioannou, A., Giangregorio, L., Kvern, B., Boulos, P., Ioannidis, G., and Adachi, J. (2004). "The osteoporosis care gap in canada," BMC Musculoskeletal Disorders 5(1), 1, doi: $10.1186 / 1471-2474-5-11$.

Pereira, D., Haiat, G., Fernandes, J., and Belanger, P. (2017). "Simulation of acoustic guided wave propagation in cortical bone using a semi-analytical finite element method," 
The Journal of the Acoustical Society of America 141(4), 2538-2547, https://doi .org/ 10.1121/1.4979695, doi: 10.1121/1.4979695.

Predoi, M. V., Castaings, M., Hosten, B., and Bacon, C. (2007). "Wave propagation along transversely periodic structures," The Journal of the Acoustical Society of America 121(4).

Rico, H. (1997). "The therapy of osteoporosis and the importance of cortical bone," Calcified Tissue International 61(6), 431-432, doi: 10.1007/s002239900361.

Ritzel, H., Amling, M., Pösl, M., Hahn, M., and Delling, G. (1997). "The thickness of human vertebral cortical bone and its changes in aging and osteoporosis: A histomorphometric analysis of the complete spinal column from thirty-seven autopsy specimens," Journal of Bone and Mineral Research 12(1), 89-95, doi: 10.1359/jbmr.1997.12.1.89.

Rozental, T. D., Deschamps, L. N., Taylor, A., Earp, B., Zurakowski, D., Day, C. S., and Bouxsein, M. L. (2013). "Premenopausal women with a distal radial fracture have deteriorated trabecular bone density and morphology compared with controls without a fracture," The Journal of Bone \& Joint Surgery 95(7), 633-642, doi: 10.2106/JBJS.L. 00588.

Sansalone, V., Naili, S., Bousson, V., Bergot, C., Peyrin, F., Zarka, J., Laredo, J., and Haïat, G. (2010). "Determination of the heterogeneous anisotropic elastic properties of human femoral bone: From nanoscopic to organ scale," Journal of Biomechanics 43(10), 1857 - 1863, doi: http://dx.doi.org/10.1016/j.jbiomech.2010.03.034.

Sarvazyan, A., Tatarinov, A., Egorov, V., Airapetian, S., Kurtenok, V., and Gatt, C. J. (2009). "Application of the dual-frequency ultrasonometer for osteoporosis detection," Ultrasonics 49(3), 331 - 337, http://www.sciencedirect.com/science/article/pii/ 
S0041624X08001790, doi: https://doi.org/10.1016/j.ultras.2008.10.003.

Sawbone (1997). "Pacific research laboratories," P.O. Box 409, Vashon, WA 98070,USA .

Seeley, D. G., Browner, W. S., Nevitt, M. C., Genant, H. K., Scott, J. C., Cummings, S. R., and (1991). "Which fractures are associated with low appendicular bone mass in elderly women?," Annals of Internal Medicine 115(11), 837-842, doi: 10.7326/ 0003-4819-115-11-837.

Stein, E. M., Rosete, F., Young, P., Kamanda-Kosseh, M., McMahon, D. J., Luo, G., Kaufman, J. J., Shane, E., and Siffert, R. S. (2013). "Clinical assessment of the 1/3 radius using a new desktop ultrasonic bone densitometer," Ultrasound in Medicine and Biology 39(3), 388-395, doi: 10.1016/j.ultrasmedbio.2012.09.024.

Ström, O., Borgström, F., Kanis, J. A., Compston, J., Cooper, C., McCloskey, E. V., and Jönsson, B. (2011). "Osteoporosis: burden, health care provision and opportunities in the eu", journal="archives of osteoporosis," 6(1), 59-155, doi: 10.1007/s11657-011-0060-1.

Tatarinov, A., Sarvazyan, N., and Sarvazyan, A. (2005). "Use of multiple acoustic wave modes for assessment of long bones: Model study," Ultrasonics 43(8), 672 - 680, doi: http://dx.doi.org/10.1016/j.ultras.2005.03.004.

Thakare, D. R., Abid, A., Pereira, D., Fernandes, J., Belanger, P., and Rajagopal, P. (2017). "Semi-analytical finite-element modeling approach for guided wave assessment of mechanical degradation in bones," International Biomechanics 4(1), 17-27, https: //doi.org/10.1080/23335432.2017.1319295, doi: 10.1080/23335432.2017.1319295.

Tran, T. N. H. T., Le, L. H., Nguyen, V. H., Nguyen, K. C. T., and Sacchi, M. D. (2015). "Sensitivity analysis of leaky lamb modes to the thickness and material properties of cor- 
tical bone with soft tissue: A semi-analytical finite element based simulation study," in Ultrasonics Symposium (IUS), 2015 IEEE International, IEEE, 45 Hoes Lane Piscataway, NJ 08854-4141 USA, pp. 1-4, doi: 10.1109/ULTSYM.2015.0510.

Tran, T. N. H. T., Le, L. H., Sacchi, M. D., and Nguyen, V.-H. (2018). "Sensitivity analysis of ultrasonic guided waves propagating in trilayered bone models: a numerical study," Biomechanics and Modeling in Mechanobiology 17(5), 1269-1279, https://doi .org/10. 1007/s10237-018-1025-8, doi: 10.1007/s10237-018-1025-8.

Wilcox, P. D., Lowe, M. J. S., and Cawley, P. (2001). "Mode and transducer selection for long range lamb wave inspection," Journal of Intelligent Material Systems and Structures 12(8), 553-565, https://doi.org/10.1177/10453890122145348, doi: $10.1177 / 10453890122145348$.

Wilcox, P. D., Lowe, M. J. S., and Cawley, P. (2005). "The excitation and detection of lamb waves with planar coil electromagnetic acoustic transducers," IEEE Transactions on Ultrasonics, Ferroelectrics, and Frequency Control 52(12), 2370-2383, doi: 10.1109/ TUFFC . 2005.1563281.

Xu, K., Minonzio, J. G., Ta, D., Hu, B., Wang, W., and Laugier, P. (2016). "Sparse svd method for high-resolution extraction of the dispersion curves of ultrasonic guided waves," IEEE Transactions on Ultrasonics, Ferroelectrics, and Frequency Control 63(10), 15141524, doi: 10.1109/TUFFC.2016.2592688. 